\title{
Young women in science and technology: the importance of choice
}

\author{
Angeliki Dimitriadi
}

\author{
Correspondence: angeliki.dimitriadi@ \\ gmail.com \\ Hellenic Association of University \\ Women, Voulis 44A, Athens 10557, \\ Greece
}

\begin{abstract}
Despite significant improvements in the last couple of years, women are still under-represented in science and technology, both in the academic and private sector. This is due to a variety of reasons, mostly related to the role allocated to women in modern society as well as pre-existing prejudices that form glass ceilings while encouraging male presence in the workplace. It is also however, a result of information or lack of, which places young women in difficult position of making a career choice, with little knowledge of available possibilities. What seems to be missing are good role models that could act as inspiration and source of information and guidance, and offer a glimpse into the reality of being a female employed in the field of science and/or technology. Parents, teachers, and career guidance counselors all have a significant role in assisting or hindering the way young women chose their career paths and that choice begins early on from school, all the way through to higher education. Choice, essentially, and factors that determine it as well - as ways of encouraging female participation in science and technology - are the focus of the present article, which is based on results from the European project Information for a choice: empowering young women through learning for scientific and technological career paths, realized under the 6th Framework Program. As this article will show, the promotion through the usage of new technologies, of role models, is crucial in breaking the existing stereotype of women in science, engineering and technology. Science is often rejected as a career choice due to limited information available and positive role models to encourage young girls in participating. Career orientation offered at school through the usage of new technologies is an important step in that direction; however, particularly in countries where the family unit is especially influential in career decisions, parents must be brought in and educated on the possibilities available. Mass media also play an important role in introducing and sustaining stereotypical images of women in particular professional roles, thus, any outreach solutions need to include them.
\end{abstract}

Keywords: Science and technology, Role models, Stereotypes, Transferability

\section{Background}

The 2011 Global Gender Gap Report in its opening paragraph stated that 'Given the complexity of the world today [...] we must commit to a new mindset, one that discards old prejudices and inertia and instead commits to new ideas and new solutions. Empowering and educating girls and women and leveraging their talent and leadership fully in the global economy, politics, and society are fundamental elements of the new models required to succeed in today's challenging landscape'. This is clearly a theme embraced by the 
European Union, which is already facing a significant gender gap especially in science, engineering and technology (SET). According to the European Commission, women constitute $40 \%$ of the university graduates in science, mathematics, and computing, and $32 \%$ of all career researchers. The gap widens if one moves beyond the education and factors in future employment and wage earnings.

Despite the significant efforts in closing the gender gap, Europe will still need approximately one million researchers in the coming decade-(Khasan 2012). With this in mind an initiative began, spearheaded by the "Science: it's a Girl Thing" campaign ". The video resulted in an outcry from feminists and prominent researchers, who argued that it simply reinforced stereotypes of women doing 'girly' things, in high-heeled shoes and painted toe nails. The Commission's message was clear; Science can be a feminine endeavor. Despite failing significantly short of what it hoped to achieve, the campaign brought once again to the foreground a fundamental question: Why do not girls participate in science engineering and technology more? The following article seeks to present the findings of the IFAC project 'Information for a choice: empowering young women through learning for scientific and technological career paths', which investigated the low participation of young girls in SET from high school to university level. Beginning with a short presentation of the project, a discussion ensues on the factors identified by the project as most critical in influencing young girls' decision-making process and to conclude with a more detailed examination of the importance of role models as mentors and inspirational influence for young women in the early stages of choosing career paths.

\section{The IFAC project}

The IFAC project ' Information for a choice: empowering young women through learning for scientific and technological career paths' aimed at documenting the current participation of young women in science and technology, primarily focusing on the reasons why there is a significant differentiation between female and male participation. The project targeted young women in high school, ages between 16 and 18, at a time when they are asked to choose their education and future career paths which are influenced by their societal and school environment. The project aimed in reaching a balance between informing and inspiring young girls towards science and technology. In order to unveil the obstacles young women face when designing their educational and career paths, workshops and information events (seminars) took place, which engaged the participation of experts, which intensified the collaboration between the partners and enabled the promotion of the main results of the project and its aims to a wider audience, including universities and schools.

Efforts were made to broaden the target audience to include not only research institutes and centers specialized in equality and gender issues, equal opportunities in employment, and sensitization of women towards Science, Engineering and Technology (SET), but also guarding and parental groups, career centers and counselors, and policy makers in the field of employment. In the past many researches have stressed the fact that for young people, it is becoming increasingly harder to find the appropriate career path (St John-Brooks 1996). In the era of lifelong learning, it became more and more essential for them to receive accurate information and good career guidance in order to 
understand the world of work, choose an occupation, and have a smooth transition from school to employment. Therefore, it is important not only to improve the 'fit' between the skills and the ambitions of young persons, but also to give them the opportunity to navigate their way in resources that will lead them to satisfying and productive career options without exclusions which women are experiencing.

The IFAC project supported the idea that if young women have access to accurate information regarding their options in technological professions and science careers, obstacles to be faced, and successes to be achieved, they could be better prepared to decide and thus participate. The key is information and positive role models. With ten participants across five member states and using quantitative and qualitative data, it drew comparisons between the countries of the Northern, Central, and Southern Europe, brought best practices to the foreground transferability options, and above all examined the decision-making process made by young women about entering SET.

Why, however, is the inclusion of young women in SET important? As it has been noted during the first IFAC thematic workshop ${ }^{c}$, their inclusion or exclusion has, in fact, practical as well as moral applications.

- In economic terms the involvement of women in SET is a necessity. They are regarded as an important factor of growth and development both in the case of developed and developing countries. Especially in the latter case, women's underutilization in -SET is equated with a loss in human resources. This can act as a major impediment to economic growth since a critical mass of scientists and engineers could help to ensure sustainability.

- In practical terms the involvement of women in SET is essential. A recent report notes that 'A more diverse workforce, which reflects a wider variety of experiences and views, can greatly benefit the SET enterprise as well as society as a whole'. They bring different strengths (and limitations) to science than men.

- In moral terms the involvement of women in SET is a requirement. A declaration following the Fourth World Conference on Women stated that gender equality is 'an inalienable, integral, and indivisible part of all human rights and fundamental freedoms'. Lack of access to SET for women creates cultural barriers for their children, especially their daughters.

The project sought not only to identify the main reasons behind low female participation in SET, but also encourage the involvement of young women in SET through the promotion of initiatives and role models. The core finding of the project was that women do not chose 'hard' sciences, because they do not have access to all the information of what that choice would entail and when they do it tends to be negative and biased. Young girls lack access to positive information and particularly role models - women who succeeded before them in overcoming stereotypes and breaking through the glass ceiling.

\section{Results and discussion}

\section{Female participation in SET?}

Based on available resources (statistics, surveys, and analysis), which show that women are under-represented in science and technology, the project focused on the two most 
significant causes for female exclusion in the field of SET: the pre-existing stereotypes that reinforce male dominance in the workplace and the lack or limited information about career paths.

Educational choices are increasingly determined by future 'employability'. Rapid technological changes and globalization have affected the organization and the content of work, and both boys and girls opt for scientific and technological subjects in order to secure their employability. However, although girls are considered to perform better during and after the end of their high school education, more boys than girls will follow higher education studies in sciences and technology and even fewer will follow a career in SET. This phenomenon appears to be common in many educational systems, and a series of surveys prove that schools have a responsibility for the discrepancy between boys and girls.

Worldwide surveys (e.g., OECD 2006, 2011, EURYDICE 2011) show that while women are not formally excluded from any level of education, nevertheless, social stereotypes and traditional concepts for women's role create a status of informal exclusion of girls, thus guiding them to make different educational and professional choices from boys. Additionally, despite the increasing demand for qualified personnel in research and technology and despite the high rate of women graduates from higher education, women are still underrepresented in science and technology. On the other hand, they retain high employment numbers in sectors such as domestic work, education (teachers and trainers), and medicine. Surveys note that the highest concentration of women in the field of research and industry is found in biology, health services, and pharmaceutical companies, whereas there is very low representation in sciences like physics, information communications technology (ICT), and engineering. The reasons for that are numerous and are studied extensively in the literature (Hayes and Flannery 2000; Henwood 1998).

Young persons while trying to choose their future studies and career are under the influence of various factors. We know that young women have deep-rooted educational prejudices that science and technology favor male applicants (Zhu 2006), they lack self-esteem in the high technology fields despite their often much higher grades and performance than their male counterparts (ibid), and they struggle to balance family and working life often feeling that the former has to take precedence over the latter. The IFAC project, however, attempted to condense the extensive research available on low female participation in SET and focus on three broader categories that directly or indirectly affect the career choice of young women: the family unit and particularly the background, education and experiences of the parental figure most influential in the family, the school and particularly the science teachers, and finally the gender stereotypes sustained and propagated through the media (internet, films, TV, and magazines).

\section{The family unit}

The process of choosing a career is 'largely based on estimating one's ability and values, skills, and abilities required for success in a given occupation, and estimating the work values that will be satisfied by the various occupational alternatives available' (Brown 2002 cited in Beauregard 2007, p. 112). Family influences the decision-making process and inevitably the career choice.

A mother's field of work relates to her daughter's choice of occupation (Corcoran and Courant 1987) especially if the mother is employed in 'traditional' female jobs, like 
education, administration, or domestic work. Work-bound youth's parents frequently teach skills that provide her with a broader understanding of her own aptitudes contributing to career choice (Ferry 2006). The process often takes place unconsciously, since individuals tends to choose an occupation that enables them to satisfy needs that were unfulfilled in their childhood and actualize dreams passed on to them by their family' (Pines and Yanai 2001 cited in Beauregard 2007, p. 114).

The parental influence is strong on gender roles and stereotyping (see Booklet for Career Counsellors, IFAC project) in relation to the cultural milieu and the socialization perspectives that conspire to turn girls away from science-related careers towards careers that are considered more 'convenient' for family, less demanding, and which require fewer educational prerequisites. As it has been emphasized during the first thematic workshop of the IFAC project (see Artzmann and John 2008), parents and especially mothers influence their girls to their educational choices because studies, in their perception, are not necessarily associated with the employment, with the exception of certain fields such as medicine. Furthermore, when they encourage the girls to study mathematics and physical sciences, they perpetuate negative information problems of reconciling family and working life, glass-ceiling, male-dominated industry, etc. which, in effect, discourage girls from further pursuing relevant career choices or higher positions.

However, one should factor in the educational level of the family, especially the mother, the social status, personality, and belief system, as well as the impact exercised by collective experiences. Within a culture of close-knitted families where the opinion of the elders is respected and taken into significant consideration, it is more likely to see a direct impact on career choices than on families that encourage individuality and independent decision-making. It is also important to factor in the economic status of the family. The work-bound youth has very different educational and occupational goals from the college-bound youth as stressed by Ferry (2006). When the youth knows that she will need to work and earn an income early on, she tends to choose educational pathways that will enable her to find a job sooner rather than later. This often means that education is used to access the job market and ensure workplace readiness. This again means that in the long-run, certain career paths open but future opportunities also remain closed (idem).

In the IFAC project, this was seen across the board, in all the participating countries. It was also evident in the role model interviews that when the family unit was willing to support financially, emotionally, and socially the woman, the career choice made was much more based on her skills, interests, and abilities and much less on workplace readiness. In short, the women who choose to navigate the 'complex' pathway of SET have significant support from the family unit or at least, no obvious opposition.

\section{Classroom experience}

In the IFAC project, the classroom experience (Karpodini-Dimitriadi 2008) was stressed, sometimes more so, than the family unit. It is a systemic factor of huge significance since indirectly through the classroom stereotypes, barriers and identity are constructed and deconstructed. Education is the cornerstone of choice, since it enables - or at least should enable - the youth in making an informed choice based on knowledge, information, interests, and understanding of one's skills. According to Zhu (2006), as a special social 
discourse, education itself is 'constructed by historical and other social discourses. It simultaneously constructs men and women's mentality of gender differences regarding their roles in family and society, which in turn affects their career choices (ibid 2006, p 5). Essentially, school should promote gender equality, by giving equal support, access, and encouragement to both girls and boys in mathematics and sciences. Does this really happen?

The educational system of the five participating member states was of significance, since the project wanted to see the extent to which they were similar in their approach to reaching out to young girls in math and science. The project found that the educational systems of South, Central, and North Europe have interesting similarities in regard to gender equity. In theory they all share a commitment to equally encourage and assist girls and boys. In reality, however, most countries require changes in their educational system in order not only to assist girls in nonstereotypical roles, but also to promote among boys the different concepts and thinking processes in gender equality. As it has been stressed during the first IFAC thematic workshop in many parts of the world, female enrolment is substantially lower, especially at the secondary level; during schooling years, girls are not inspired enough by their teachers to become involved in science and mathematics; girls show a lack of confidence in their mathematics and science abilities; although girls' science achievement levels are frequently equal to or even exceed those of the boys in early primary school, they usually drop in secondary school. Additional factors are classroom interactions between girls and boys and the often hostile and unaccommodating climate shown by teachers within classrooms for girls interested in science and technology.

Classroom experiences is also a factor (ibid), which differentiates learning approach and achievement expectations; while girls very often are neither given adequate information about career possibilities requiring competency in advance mathematics and/or sciences, nor they are introduced to women role models with successful math and/or science careers; although in general, role models can be an important factor in elevating a young person's aspirations. As a result many pupils hold gender stereotype attitudes towards a range of occupations, associating certain characteristics with a particular gender (for example, women are more caring, better at talking to people, etc.; men are stronger, fitter, and more technical and practical). The psychological differential transforms itself into a social dynamic issue - SET is intrinsically linked with masculine characteristics that in turn relate to degrees of status and power. In the end, from the classroom to the everyday life, girls tend to be 'guided' (often unconsciously) towards a 'feminine' and thus lesser social status and power instead of being informed of the variety of options available to them and a broader vision of career choices. School curricula, the teaching practices, and the language teachers usually use reproduce the stereotypes of roles starting from grammar and leading up to the semantics level, while the system of vocational training also leads to restriction of girls' professional horizons.

In the end one could argue that at the core of the discussion is the issue of gender stereotyping and its conscious or unconscious promulgation.

\section{Gender stereotypes}

In January 2005, the then president of Harvard University, Lawrence Summers, suggested that the under-representation of women in science and engineering might be due to, at least in part, inherent sex differences in cognitive abilities central to math and science. His 
comments were seen by the majority of his peers and wider audience to reflect a widely held yet no-longer publicly pronounced stereotype of the difference in the natural abilities between men and women. However, the problem is not so much that the stereotype exists but that it has seeped in the consciousness of both men and women around the world, acting as a natural barrier to young girl's career development in fields where they otherwise might have excelled.

The gender stereotypes range from the different natural abilities (see above discussion) to the caring and nursing nature of women versus the more independent, strong, and protective nature of men. Young girls select sectors relating to health and welfare, care, applied arts, such as clothing and graphic designing to social sciences, fine arts, and humanities. Medicine is probably the only field from the core of the 'hard sciences' that female participation is steady. In contrast, boys select sectors that are related to mechanical engineering, electrical engineering, computers, finance, and enterprising fields. The sociocultural stereotypes that relate to gender (e.g., men are better leaders versus women are better with children) impact and construct occupational stereotypes (Huges 1945) since occupations at all levels have sex-linked images, and people think of men as laborers, women as secretaries, men as executives, women as nurses, etc. (see Dimitriadi 2007).

Marks and Houston (2002) in their research on girls between 15 and 17 years with high academic credentials found that their career plans were heavily influenced by what they perceived as their 'expected duty' to care for the children they would have in the future. Girls believed that at some point in their life they would have children and tended to gravitate towards career paths that they believed would offer them the option of life-work balance, or would be easier to quit in order to raise the family. What is interesting is the fact that the issue of family was not questioned; it was assumed as a natural process that would inevitably take place at some point in their lives. Like school, there is a clear lack of a broader vision of life choices, one which incorporates a balanced private and work life. Gender stereotypes seep in the spectrum of social life, affect schooling and counseling, family, and friends, and inevitably create a chicken and egg relationship with lack of information that perpetuates. We now know that 'The tendency towards gender-stereotypical preferences becomes even stronger after University, when some women's aspirations to establish a family encourage a shirt toward more traditional feminine occupational fields' (Gadassi and Gati 2009 p 904).

Gender stereotypes and the lack of information are of course interrelated since 'gender stereotypes are often caused by a lack of information; and a lack of information often is a lack of accurate information caused by the persistent circulation of stereotypes concerning SET as well as gender stereotypes' (Karpodini-Dimitriadi 2008, limited circulation). Despite the efforts of the last years to eliminate gender inequalities in the teaching curricula and teaching material, gender differentiations and stereotypes are still reproduced. It has been also noted that media and youth magazines promote values and stereotypes of various social groups thus exercising pressure on 'girls to comply with female stereotypes and rewards them with social acceptance from their parents, schoolmates, and teachers' (Arztmann and John 2008).

The effects, however, do not stop at the university level. Gender stereotyping will affect not only the career choice of girls, but also their professional development where more barriers will be encountered. According to the European Foundation for the Improvement of 
Living and Working Conditions 'most men and a large proportion of women support the traditional division of labor, find differences in salaries justifiable and regard family and childcare as being mainly the responsibility of women' (Dimitriadi 2007). Gender stereotyping is recycled by both men and women and shapes future career and life paths.

\section{The significance of role models}

One of the key themes of the IFAC project was the lack of information, which is perpetuated by gender stereotyping but also on its own a factor of stereotypical career choices by girls. What we mean is that girls make specific choices on the one hand because they are encouraged down certain paths and on the other because they are unaware or have little knowledge of alternative options.

The spotlight then has to turn to the significance of role models. Young girls usually lack knowledge of the specific characteristics of occupations, the requirements to study them, and the available career paths, time-frame and career advancement options. Supplying information should be the essence of career counseling; however, it should be taken into consideration that this is not always available or accessible to young girls. For example in Greece, public schools do not offer access to career counselors - an option which is instead available in private schools. Thus, the socioeconomic position of the family inadvertently affects the access to information of the youth. Researches have elaborated the significance of role models in the career decision-making process (Gibson 2004; DeSantis and Quimby 2004; Quimby and DeSantis 2006; Nauta and Kokaly 2001).

Role models are defined as people whose lives and activities influence another person in some way (Basoc and Howe 1979 cited in Quimby and DeSantis 2006). As Quimby and DeSantis stress 'role models may be especially important to women because a lack of female role models in nontraditional careers (e.g., engineering) has been identified as a barrier for women who choose to enter these professions' (Quimby and DeSantis 2006, p 297). As it became evident from the early stages of the project, the role models exist but are not promoted - largely a result of gender stereotyping. The stories of success are left untold, creating a vacuum where role models are needed. The IFAC project sought to 'test' the role model impact utilizing modern technology. An online database was set up, designed to attract young girls. The design, layout, and context were tested on young girls ages 16 to 18 in Germany and the Netherlands, whose input was utilized for the construction of the database. Bearing in mind the breadth and depth of the field and the various participating countries and cultural factors involved, the idea emerged of creating a short database which identified successful cases of women who entered SET, actively worked in the field, and in many cases developed also a successful family life with an appeal and a personal story is applicable to a broader European content. The purpose of the database was not to present the ideal woman. The interviews themselves were extensive, offering the reader a rare insight into the process these women underwent in choosing, pursuing, and finally succeeding in their career.

Because of the nature of the interviews (many private questions were asked), we left it up to the women to choose how much they would elaborate on their answers, or how little they would reveal. In the end we provided them with the opportunity to tell their story whichever way they felt comfortable. Women came from different backgrounds and had different family status as well as age. Although a small sample in total (21 interviews), the 
professions and careers portrayed were more than inspirational - from biotechnology and molecular biology and genetics to information technology and physics amongst the few. The majority of the participants came from engineering (eight in total), secondly from information technology (five), thirdly from physics and chemistry (four), and finally from biotechnology or biochemistry (four). Fourteen of them are married and have on average 1-2 children, with the rest either cohabiting or single. In all cases their marital status was a conscious decision, showing that although not easy, there can be a balance between private and work life. The selection was broad enough to appeal to everyone's taste and needs. Young girls visiting the data base might find a 'role model' that would inspire their future science and career choices.

Simultaneously, educational software for career choices JOBLAB (JOBLAB - The secret multimedia laboratory for vocational orientation and academic careers) was utilized specifically for the purposes of the project. It is an innovative, ICT-based electronic career guidance tool that was originally developed in Germany to encourage teenage girls to consider a broader range of career options. The software can be used by career counselors but also the target group itself, for self-exploration. The software was piloted in schools in Sweden and the Netherlands as well as Greece. Career options, pathways, detailed analysis of science jobs, requirements and options, and timeframe of studies were fed into the system, as well as interviews (in depth) with role models, at least one per profession along with contact details of those who had agreed to act as mentors. Girls were able to access the software by searching or randomly scrolling through the environment, answer questionnaires drafted by career counselors, have a profile made up of likes and dislikes, course preference, and abilities, and find career options in science and technology complemented with life stories of women.

The presentation of successful cases had a two-fold role: they acted in an informative way (what studies did the person conduct, which university, work experience, etc.) but also as mentors (by providing information regarding obstacles faced and how to overcome them). The project focused primarily on the informative role of the models; however, the resources available offered the option of 'tele-mentoring' in selected cases in order to facilitate the dissemination of information towards high school students, career counselors, higher institutions, and governmental bodies and take one step further the efforts of integrating women in engineering, technology, and hard sciences. It was a unique effort in the Greek context and a significant step in the European level.

The realization of the project had a direct effect not only on young women in high schools that could access the information through the IT information system, but also to career counselors, experts, and educators.

Two issues are also highlighted that require further investigation. The first was the issue of information itself. Girls do not just lack information. Worst, at times, they have a much distorted picture of certain professions and career paths, e.g., engineering professions, which they associated with masculinity (and thus loss of femininity). Beauregard points out to research conducted on the perceived attractiveness of individual as dating or marriage partners based on their professional choice by Seymour and Hewitt (1997), whereby undergraduate male students claimed that women studying male-dominated disciplines like engineering or physics were inherently unattractive. Women who pursue nontraditional gender jobs are rated by men as less attractive potential life partners. Essentially stepping out the box in the professional sphere is 
associated with punishment in the private sphere (see Beauregard 2007; Badgett and Folbre 2003).

The second issue that arose was that girls tended to wonder at the level of 'hardship' associated with certain profiles especially in relation to their private lives. It was important to them how many of the role models had children, how they balanced their careers and personal lives, if they had families and if not, why etc. There was an underlying issue of unwillingness to make 'sacrifices' in the short term, for potential career long-term gains, if that meant an imbalance in favor of work over private life. Marks and Houston (2002) whose research focused on a similar age group as the one in the IFAC project, found that the career plans of young girls are influenced by family responsibilities, which they do not have yet but are brought up with the expectation of having in the future $\mathrm{p}$.

Role models do not necessarily assist directly in career choices. Seeing or meeting a successful bioengineer for example does not mean that the girl will also choose to pursue a bioengineering degree. She might, however, realize that she can pursue a career path in another SET-oriented profession of her preference, which is inspired by the story and success of the role model presented to her. Increasing exposure to role models in a variety of professions can assist female students in making career choices (Quimby and DeSantis 2006, p. 304).

\section{Conclusions}

With the above in mind, the IFAC project produced a series of policy recommendations (Hake 2008) aimed not specifically at the participating countries to the project but to the wider audience.

It can be said that the main objective of attracting women in SET can be accomplished by substituting a very hegemonic and therefore highly selective professional culture by a more diversified culture (Hanappi-Egger 2008). The topic of women in SET is a complex issue ranging from informational to organizational issues.

Awareness and sensitivity and training for teachers and kindergartens, schools and colleges, and adult educators are seen as an important first step in the right direction along with curricula reform as part of institutional change.

Great influence is also exercised by guidance and career counselors, when they advise girls on their educational and career choices. Often, counselors and advisors, even if they do it unconsciously, shape their advices on what fits a girl based on societal images of the role of a woman. It is therefore imperative to establish a gender-sensitive career counseling (Karpodini-Dimitriadi 2008) that will provide accurate information for careers in higher scientific education and the employment opportunities SET offers in high-profile jobs. In order to assist girls to make educational and career choices that will affect their lives, they must present and promote successful female role models who could act as mentors for young women.

Mentoring and role model visibility is an additional step in targeting girls towards SET. The down side of it so far seems to be that the focus is more often not on the work-life balance which appears as a woman's issue and the presentation of role models resembling the superwoman, an unrealistic portrayal which can restrict the role models potential to act in an influential manner. The role model issue is directly linked to the issue of public image of science and scientists. 
However, change can be accomplished only by changing the operating systems of our institutions. A gender-inclusive approach is needed to include men as well as women in the discussion, and curricula reforms have to be taken seriously. Additional funding and establishing quotas in institutions are needed to monitor gender equality and create a culture of success for women in SET (Wachter 2008). After all 'It's not the women that need fixing, it's the institutions!' (ibid). In order for this to be achieved, transferability of best practices, new ideas, and policies is essential. Why is transferability of initiatives important? Transferability provides resources, knowledge, and experience to meet the needs of young girls concerning their future educational and career choices. It can be a powerful tool in assisting all stakeholders in pursuing their own strategies for raising student awareness towards gender issues and educational and career options. It facilitates the development and implementation of integrated approaches for addressing more effectively gender issues, educational needs, and priorities. Teachers, career counselors, and researches can compile good practices, experiences, implemented ideas, projects, and initiatives and use them as an on-going process to lifelong learning and continuing professional development.

As the majority of the European countries face similar problem, the transferability suggestions are valuable to most (see KTH 2008). However, transferability is not an easy issue. It entails different factors and components and it is largely determined by quality. Highly valued practices and actions are usually linked with high transferability. However, transferability does not alone determine an initiative's or a project's worth. There are many issues that must be considered. Generally, transferability presupposes similar environments (educational or geographical) in order to avoid misperceptions. The ability for the transfer of an initiative is highly dependent on the working methods, and it is linked with the issues of applicability (how relevant it is), adaptability (to the local circumstances), and complementarity (to existing policies and strategies). Adjustments to local conditions must be done. The presentations give information about what can be done based on the experiences of the participating countries. They also show that initiatives must be well prepared before they are delivered. A poor performance will convince young girls that a career in SET is not suitable for a young woman. The selected cases also showed that an initiative could be used to give good PR for a school or company instead of making young women interested in a career in SET. One mission must not exclude the other, and a combination of the two aims is advised. When it comes to initiatives directly addressed to young girls, attention should be paid to those who want to complement ordinary education with an initiative.

In order to respond to the problem of under-representation and reverse this phenomenon, it is important to have a holistic policy and actual involvement of all interested bodies, both on the national and European level, aiming at guaranteeing female scientist employment and striking a balance in participation of both genders in scientific jobs and finance communication networks among women. The choice of career is a lifelong process that demands an accurate and in depth perception of ability, potential, and achievement, and it is one of the major areas of concern for young people nearing the end of their schooling. Interventions should be expanded also to the primary education because the results there are much more conspicuous and the interventions can be more substantial at pupils of younger age.

The under-representation of women in workforce related to SET careers - academia included - is a common issue in all countries regardless geographical areas, as the findings show. The problem still remains even in countries, where initiatives or projects have been 
implemented like Sweden with moderate results (e.g., summer science camps for girls). This brings us to the important role of education and its type; it came out that we do need not only an education of high standard, but we also need the mechanisms that will support it. The guidance system is among the most important aspects, a system that will involve all actors and stakeholders (school teachers and professors, school associations, parents, and the business world) so young children, especially girls, receive all the required information in order to make proper choices that will allow them to pursue successful careers and help them to be happy in their lives.

In most European countries, there is a trend to undertake innovative actions in order to motivate young schoolgirls towards science and technological careers. The most successful ones are those that combine information with hands-on experience. The initiatives (such as summer days, and summer camps) can have a positive influence in increasing the number of female students at the science and technological faculties. However, the sustainability of the different actions proves to be crucial. In order to be achieved, the funding should be ensured coming from a broad range of sources, both state and private. The role of universities and technical colleges is very important. They can offer their laboratories for practical experience, motivate their students to serve as role models, and contribute to the empowerment of young female teenagers to study in the domain that traditionally are classified as male.

Summarizing, the project achieved its aims via the presentation of women from SET professions as role models, through the supply of best practices, encouraging young women to choose academic and career choices in SET. The exchange of best practices extracted valuable information for alternative forms related to enticing young women in choosing a technological profession or applying best practices to maintain women in technological and scientific careers. Stimulating young women towards science and engineering is crucial to close the gender gap and an important step in achieving parity in the long term. In order for this to happen, it is imperative to reach a wide audience. The workshops and seminars organized during the development of the project played a crucial role on creating the opportunities for the selection and exchange of identified best practices in attracting, recruiting, and retaining women in scientific and technological careers in both public and private sector. They also provided a fertile ground for discussion by presenting ideas, successful and unsuccessful initiatives, programs and mechanisms, and by stipulating policy suggestions in order to encourage young women to select studies and careers in SET.

\section{Methods}

The article focuses on the results of the IFAC project on the participation of young girls in SET. By using existing literature in the field of gender as well as the results of the project (produced through cross-comparison of best practices, researches, and projects across the five participating countries) the article showcases the key issues identified as 'barriers' to the participation of young women in SET.

\section{Endnotes}

${ }^{\text {a }}$ The video has been removed from the internet.

b The analysis and results presented in this paper draw from the IFAC project (2006 to 2008) originally realized and funded by the European Union 6th Framework 
program, its deliverables and its thematic workshops. The content of this article does not reflect the official opinion of the European Union nor of the partners in the project. Responsibility for the information and views expressed here lies entirely with the author. The project was realized with the participation of ten partners from five European Union countries: Greece (EVREMATHIA AE, EKEPIS, SEE), the Netherlands (NoorderpoortCollege), Austria (Center for Social Innovation, Vienna University of Economics and Business Administration), Germany (Information Multimedia Company), and Sweden (Royal Institute of Technology, University of Halmstad). Amongst the project's key deliverables were a policy paper and a cross-national analysis of past research projects in the participating countries (http://cordis.europa.eu/search/index.cfm?fuseaction=proj. document\&PI_RCN=9464968).

${ }^{\mathrm{c}}$ IFAC, First thematic workshop minutes, Athens, 30/11 - 1/12/2006 (unpublished).

\section{Competing interest}

The author declares no competing interests.

Received: 20 November 2012 Accepted: 7 May 2013

Published: 24 May 2013

\section{References}

Artzmann, D, \& John, S. (2008). Promoting young women in SET: lessons learners. A cross-national analysis of past research projects. Vienna: IFAC project.

Badgett, MVL, \& Folbre, N. (2003). Job gendering, occupational choice and the marriage market. Industrial Relations, 42, 270-298.

Beauregard, A. (2007). Family influences on the career life cycle. In MF Ozbilgin \& A Malach-Pines (Eds.), Career choice in management and entrepreneurship: a research companion. Cheltenham: Edward Elgar.

Corcoran, ME, \& Courant, PN. (1987). Sex-role socialization and occupational segregation: an exploratory investigation. Journal of Post Keynesian Economics, 9, 330-346.

DeSantis, AM, \& Quimby, LJ. (2004). Self-efficacy as a mediator between contextual variables and career choice. Washington, DC: Poster session presented at the 113th Annual Convention of the American Psychological Association.

Dimitriadi, A. (2007). Communicating gender issues: good practices for gender equality. Athens: 'Ladies First' EQUAL ॥ project.

EURYDICE. (2011). Science education in Europe: national policies, practices and research. Brussels: Education, Audiovisual and Culture Executive Agency.

Ferry, NM. (2006). Factors influencing career choices of adolescents and young adults in rural Pennsylvania. Journal of Extension, 44, 3RIB7.

Gadassi, R, \& Gati, I. (2009). The effect of gender stereotypes on explicit and implicit career preferences. The Counseling Psychologist, 37, 902-922.

Gibson, DE. (2004). Role models in career development: new directions for theory and research. Journal of Vocational Behavior, 65, 134-156.

Hake, BJ. (2008). Towards equal opportunities in SET careers: policy recommendations of the IFAC project. Athens: IFAC project. (limited circulation). SEE: Policy Paper.

Hanappi-Egger, E. (2008). Welcoming speech (3rd Thematic Workshop of the IFAC project). Vienna, Austria.

Hayes, E, \& Flannery, D. (2000). Women as learners - the significance of gender in adult learning. San Francisco: JosseyBass.

Henwood, F. (1998). Engineering difference: discourses on gender, sexuality and work in a college of technology. Gender and Education, 10, 35-49.

Huges, EC. (1945). Dilemmas and contradictions of status. The American Journal of Sociology, 50, 353-359.

John-Brooks, SC. (1996). Educational and career guidance: what works. The OECD Observer, 202, 37-40.

(2000). E Karpodini-Dimitriadi (Ed.), Preparing young girls for science and technology careers: information booklet for career counselors. Athens: EKEPIS and E.

Khasan, O. (2012). E.U.'s 'Science, it's a girl thing' campaign sparks a backlash. http://www.washingtonpost.com/blogs/ blogpost/post/eus-science-for-girls-campaigns-spark-a-backlash/2012/06/22/gJQAOi1HvV_blog.html. Accessed 27 July 2012

KTH. (2008). Transferability report. Stockholm: The Royal Institute of Technology.

Marks, G, \& Houston, DM. (2002). The determinants of young women's intentions about education, career development and family life. Journal of Education and Work, 15, 321-336.

Nauta, MM, \& Kokaly, ML. (2001). Assessing role model influence on students' academic and vocational decisions. Journal of Career Assessment, 9, 81-99.

OECD. (2011). Report on the gender initiative: gender equality in education, employment and entrepreneurship. Paris: OECD Library.

OECD. (2006). Women in scientific careers: unleashing the potential. Paris: OECD, OECD Library.

Quimby, JL, \& DeSantis, AM. (2006). The influence of role models on women's career choices. The Career Development Quarterly, 54, 297-306. 
Seymour, E, \& Hewitt, NM. (1997). Talking about leaving: why undergraduates leave the sciences. New York: Westview. Wachter, C. (2008). Of hot potatoes and cold showers: some critical remarks on women and SET (3rd Thematic workshop of the IFAC project). Vienna, Austria.

Zhu, H. (2006). Education \& women's career choices: findings from a case study on women's informal learning pathways to IT work. Ontario Institute for Studies in Education of University of Toronto: Paper presented at the conference Work and Lifelong Learning Research Networks.

doi:10.1186/2192-5372-2-5

Cite this article as: Dimitriadi: Young women in science and technology: the importance of choice. Journal of Innovation and Entrepreneurship 2013 2:5.

Submit your manuscript to a SpringerOpen ${ }^{\odot}$ journal and benefit from:

- Convenient online submission

- Rigorous peer review

- Immediate publication on acceptance

- Open access: articles freely available online

- High visibility within the field

- Retaining the copyright to your article 